\title{
Elastic band ligation of hemorrhoids using flexible gastroscope
}

\author{
Hadi Abd Zaid Al-Khattabi, ${ }^{a}$ Ali Azeez Ali, ${ }^{a}$ Hameed Hussein Al-jameel, ${ }^{a}$ Ali Mansoor Al-Ameri ${ }^{b}$
}

\author{
${ }^{a}$ Al-Hussein Medical City, Kerbala, Iraq. \\ bDepartment of Microbiology and Immunology, Department of Microbiology and Immunology, College of Medicine, University of Kerbala, Iraq. \\ Correspondence to Hadi Abd Zaid Al-Khattabi (email: alkattabih12@yahoo.com). \\ (Submitted: 23 September 2016 - Revised version received: 14 October 2016 - Accepted: 20 October 2016 - Published online: 26 March 2017)
}

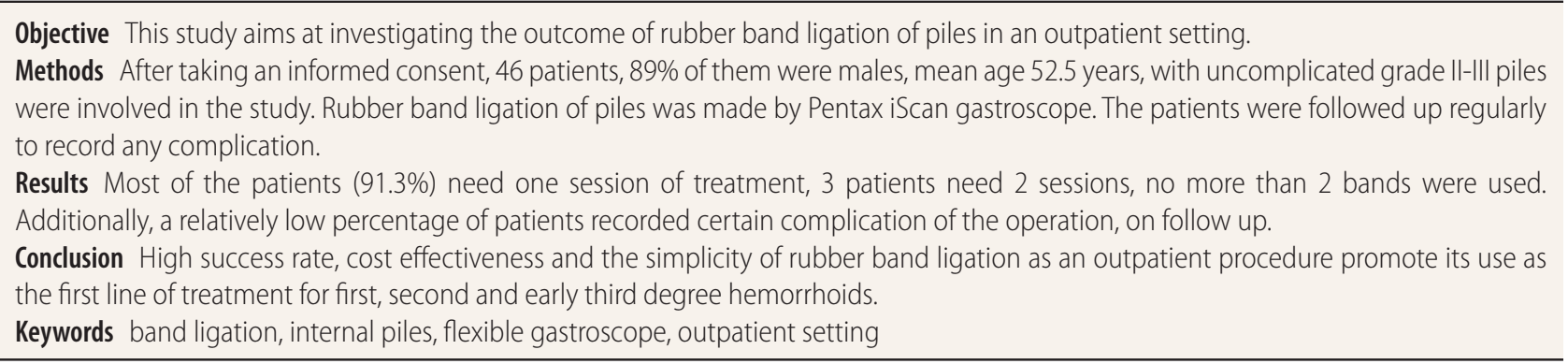

\section{Introduction}

Internal hemorrhoids are initially managed conservatively. The conservative therapy includes life-style changes such as increased fiber and liquid intake and regular cleansing. This might be combined with local anesthetic and antiphlogistic medication. ${ }^{1,2}$ More than $90 \%$ of patients with symptomatic piles can be treated conservatively or by rubber band ligation. Infrared coagulation and cryotherapy are also the options, but are no longer commonly applied. ${ }^{3}$ Since the early 1960s, the treatment of choice for persisting internal hemorrhoids is elastic band ligation by means of a rigid proctoscope (Barron ligation). ${ }^{4,5}$ The ligation of hemorrhoids is widely used as an alternative method for the treatment of internal symptomatic hemorrhoids and has replaced hemorrhoidectomy in $45 \%$ of cases. ${ }^{6}$ This method gives good results in $69-94 \%$ of cases. Although it is not associated with the problems that follow the typical surgical treatment of hemorrhoids. ${ }^{7-10}$

The RBL method is not free of complications and even deaths have been reported in immunosuppressed patients. ${ }^{11,12}$ Though considered as a safe, simple and effective procedure, studies show complications like recurrence, pain, bleeding and even pelvic sepsis in some cases. There is a wide range of recurrence rate from 8 to $30 \%$, greatest for grade III hemorrhoids. Pain is common for a few hours following rubber band ligation $(\mathrm{RBL})$ and occasionally patients experience severe pain so as to require admission to hospital. ${ }^{13-16}$ On the other hand, a flexible endoscope with a ligation cap that is employed for the ligation of esophageal varices was tested to treat internal piles by some researchers. ${ }^{17-20}$ The advantages of a flexible endoscope might be summarized by maneuverability beside photographic documentation and a wider view field.

\section{Materials and Methods}

Forty-six patients with uncomplicated hemorrhoids (Abscess, Thrombosis) grade II-III were involved in the study (Table 1).

Patients were sedated by slow i.v. using diluted Medazolam $3 \mathrm{mg}$ and pethedine $50 \mathrm{mg}$. Pentax iscan gastroscope was used with multiband ligator device (Cook, USA) and the same was used in esophageal varices ligation.
The hemorrhoids were suctioned into the ligation cap in either retrograde or ante grade fashion. One or two hemorrhoids were ligated in each session. All treatment sessions were performed in an outpatient setting.

Patients were encouraged to consult the hospital at any time and provided with facilities to contact us at any time if developed any abnormal events.

\section{Result}

Forty-six patients, mean age 52.5 years (30-75) and most of them were males (89\%), were included in this study. Most of them referred from the surgical department. A total of 45 patients were presented with a history of attacks of bleeding. One patient presented with active bleeding, and she was unfit for surgical intervention. Most of patients need one session of treatment, 3 patients need two sessions, no more than 2 bands were used (Table 2).

On follow-up, a relatively low percentage of patients recorded certain complication of the operation as listed in Table 3.

\section{Discussion}

Hemorrhoid is a disease of all ages, gender and socioeconomic status. This study shows high male proportion. This is also found in many other studies in Karachi. Shamim et al. also show a male predominance of $74.88 \% .{ }^{21}$ It has been found that the treatment of choice is proctoscope-guided rubber band ligation and that it is cost effective. Other works are trying to evaluate usefulness of new techniques. $^{22-24}$ Similarly, the use of a flexible endoscope for hemorrhoidal elastic band ligation was further analyzed using video endoscopic anoscopy and a single-handed ligator. ${ }^{24-26}$ These studies conclude that it is a safe and efficient method with some advantages, although costs are still a major drawback.

Cazemier compared the two procedures, and he concluded that both techniques were easy to perform, 


\begin{tabular}{|c|c|c|}
\hline No. & Hemorrhoid degree & No.(\%) \\
\hline 1 & $1^{\text {st }}$ degree & $-(0 \%)$ \\
\hline 2 & $2^{\text {nd }}$ degree & $16(34.7 \%)$ \\
\hline 3 & $3^{\text {rd }}$ degree & $30(65.3 \%)$ \\
\hline 4 & $4^{\text {th }}$ degree & $-(0 \%)$ \\
\hline Total & & $46(100 \%)$ \\
\hline
\end{tabular}

\begin{tabular}{lccc}
\hline Table 2. & \multicolumn{3}{l}{$\begin{array}{l}\text { Number of sessions of RBL treatment in the included } \\
\text { patients }\end{array}$} \\
\cline { 2 - 3 } RBL sessions & \multicolumn{2}{c}{ Degree of hemorrhoids } & No.( $\%)$ \\
\cline { 2 - 3 } & $\mathbf{2}^{\text {nd }}$ degree & $\mathbf{3}^{\text {rd }}$ degree & \\
\hline Single ligation & 16 & 26 & $42(91.3)$ \\
Two sessions & 0 & 4 & $4(8.7)$ \\
\hline
\end{tabular}

\begin{tabular}{llc}
\hline Table 3. Frequency distribution of complications of the RBL \\
operation
\end{tabular}

well-tolerated and efficient. ${ }^{26}$ It was easier to perform more ligations with the flexible endoscope. No serious adverse events were reported. Additional advantages of the flexible scope were the maneuverability and photographic documentation. Treatment with the flexible endoscope seemed to be more painful and was more expensive. And he explained the more pain sensation by the learning curve he had to deal with and that more bands could be applied. ${ }^{27}$ In contrast, Wehrmann et al. found no significant difference in pain. ${ }^{28}$

Many studies evaluated the patients with threedimensional endosonography for the presence of possible sphincter defects and changes in the submucosa. They found no difference in the appearance of the anal configuration after treatment with either rubber band ligation or infrared coagulation, ${ }^{1}$ and these endosonographic findings confirmed that band ligation is a safe technique. Pain or perianal discomfort is the commonest complaints after rubber band ligation. ${ }^{13,15}$

Anorectal mucosa is sensitive to pain below dentate line. Application of bands at or below this line cause considerable

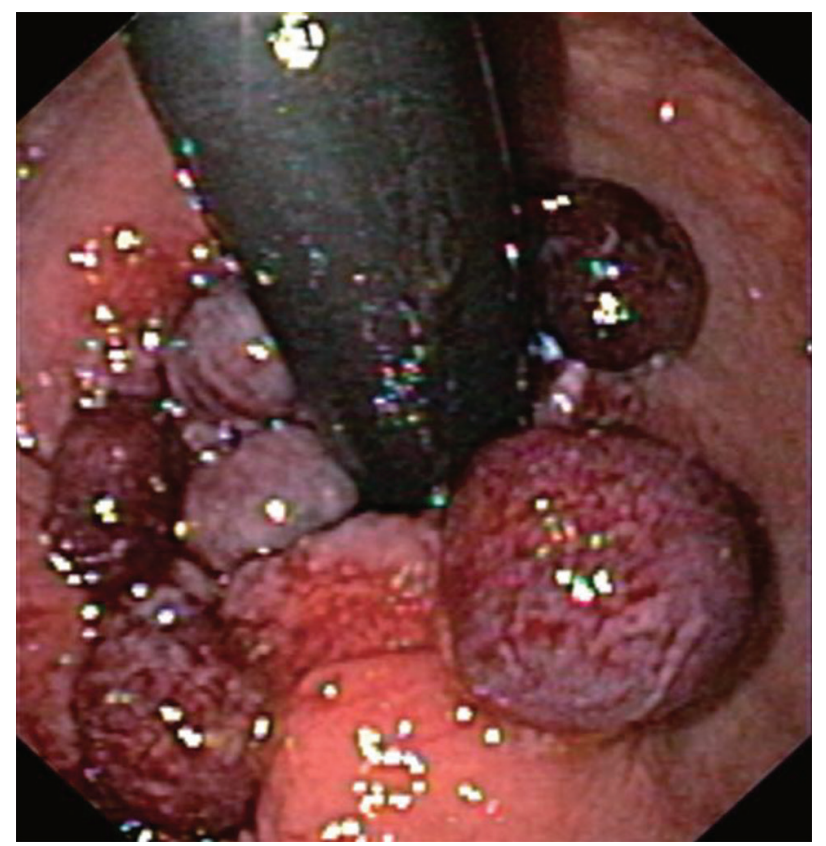

Fig 1. Rubber band ligation (RBL) of hemorrhoids is a widely used method for treatment of piles.

pain and discomfort after the procedure. This may last for a few days till the banded portion get necrosed and sloughed off. This is more common in large prolapsing hemorrhoids with a wider base. Some studies evaluated the use of a flexible endoscope equipped with a ligation cap, normally used for the ligation of esophageal varices, in treating hemorrhoids. ${ }^{16-28}$ A study from Iran shows that, with rubber band ligation, 26\% of patients reported mild and moderate pain and $1 \%$ complained of severe pain. ${ }^{28}$

A recent study from Faisalabad show that $60 \%$ of patients developed mild to moderate bleeding in the first postoperative week. ${ }^{29}$ Bernal show that $32 \%$ of the patients referred pain after ligation and $13.81 \%$ of cases were operated due to persistent rectal bleeding or hemorrhoidal prolapsed.

In summary, endoscopic ligation is an effective, safe treatment and is comparable with proctoscopic ligation. However, the treatment is more expensive.

\section{Conclusion}

Rubber band ligation is simple and cost effective procedure with a high success rate, and, as an outpatient procedure, promotes its use as the first line of treatment for first, second and early third degree hemorrhoids.

\section{Conflict of Interest}

None.

\section{References}

1. Poen AC, Felt-Bersma RJ, Cuesta MA, Deville W, Meuwissen SG. A randomized controlled trial of rubber band ligation versus infra-red coagulation in the treatment of internal haemorrhoids. Eur J Gastroenterol Hepatol. 2000;12:535-539.

2. Johanson JF, Sonnenberg A. The prevalence of hemorrhoids and chronic constipation. An epidemiologic study. Gastroenterology. 1990;98:380-386.

3. Madoff RD, Fleshman JW. American Gastroenterological Association technical review on the diagnosis and treatment of hemorrhoids. Gastroenterology. 2004;126:1463-1473.

4. Blaisdell PC. Office ligation of internal hemorrhoids. Am J Surg. 1958:96:401-404.

5. Barron J. Office ligation of internal hemorrhoids. Am J Surg. 1963;105:563-570. 
6. Bleday R, Pena JP, Rothenberger DA, Goldberg SM, Buls JG: Symptomatic hemorrhoids: Current incidence and complications of operative therapy. Dis Colon Rectum. 1992;35:477-481

7. Gehamy RA, Weakley FL: Internal hemorrhoidectomy by elastic ligation. Dis Colon Rectum. 1974;17:347-353.

8. Arabi Y, Gate House D, Alexander-Williams J, Keighley MR: Rubber band ligation or rectal subcutaneous sphincterotomy for treatment of hemorrhoids. Br J Surg. 1977;64:739-740.

9. Muller CA:Internal hemorrhoidectomy by rubber band ligation. Proctology. 1980;5:317-319

10. Wrobleski DE, Corman ML, Veidenheimer MC, Coller JA: Long-term evaluation of rubber ring ligation in hemorrhoidal disease.Dis Colon Rectum. 1980;23:478-482

11. O'Hara VS:Fatal clostridial infection following hemorrhoid banding. Dis Colon Rectum. 1980;23:570-571.

12. Russell TR, Donohue JH: Hemorrhoidal banding: A warning. Dis Colon Rectum. 1985;28:291-293.

13. Bernal JC, Enguix M, Lopez Garcia J, GarciaRomero J, Trullenque Peris. Rubber-band ligation for hemorrhoids inacolorectal unit. A prospective study. Rev Esp Enferm Dig Org Ofic Soc Esp Patologia Dig. 2005;97(1):38-45.

14. Iyer VS, Shrier I, Gordon PH: Long-term outcome of rubber band ligation for symptomatic primary and recurrent internal hemorrhoids.Dis Colon Rectum. 2004;47(8):1364-1370.

15. Komborozos VA, Skrekas GJ, Pissiotis CA:Rubber band ligation of symptomatic internalhemorrhoids: Results of 500 cases. Dig Surg. 2000;17(1):71-76.

16. Forlini A, Manzelli A, Quaresima S, Forlini M: Long-term result aft errubber band ligation for haemorrhoids. Int J Color Dis. 2009;24(9):1007-1110.

17. Trowers EA, Ganga U, Rizk R, Ojo E, Hodges D. Endoscopic hemorrhoidal ligation: preliminary clinical experience. Gastrointest Endosc. 1998; 48: 49-52.

18. Qureshi S, AzizT, Afzal A, Maher M.Rubber band ligation of symptomatic internal haemorrhoids; result of 450 cases. J Surg Pak. 2009;14(1):19-22.

19. Dickey W, Garrett D. Hemorrhoid banding using videoendoscopic anoscopy and a single-handed ligator: an effective, inexpensive alternative to endoscopic band ligationDickey W, Garrett D. Hemorrhoid banding using videoen. Am J Gastroenterol. 2000;95:1714-1716.

20. Rehan Abbas Khan, Muhammad lqbal, Farhan Zaheer, Khalid Ahsan Malik, Anis Uz Zaman, Rubber band ligation for the symptomatic hemorrhoids. What troubles the patient? Pak J Surg. 2012;28(4):266-270.

21. Takano M, Iwadare J, Ohba H, Takamura H, Masuda Y, Matsuo K, et al. Sclerosing therapy of internal hemorrhoids with a novel sclerosing agent. Comparison with ligation and excision. Int J Colorectal Dis. 2006;21:44-51.

22. Kwok SY, Chung CC, Tsui KK, Li MK. A double-blind, randomized trial comparing Ligasure and Harmonic Scalpel hemorrhoidectomyKwok SY, Chung CC, Tsui KK, Li MK. A double-blind, randomized trial comparing Ligasure and Harmonic Scalpel hem. Dis Colon Rectum. 2005;48:344-348.

23. Fukuda A, Kajiyama T, Kishimoto H, Arakawa H, Someda H, Sakai M, Seno H, Chiba T. Colonoscopic classification of internal hemorrhoids: usefulness in endoscopic band ligation. J Gastroenterol Hepatol. 2005;20:46-50.

24. Trowers EA, Ganga U, Rizk R, Ojo E, Hodges D. Endoscopic hemorrhoidal ligation: preliminary clinical experience. Gastrointest Endosc. 1998:48:49-52.

25. Dickey W, Garrett D. Hemorrhoid banding using video endoscopic anoscopy and a single-handed ligator: an effective, inexpensive alternative to endoscopic band ligation. Am J Gastroenterol. 2000;95:1714-1716.

26. Cazemier M, Felt-Bersma RJF, Cuesta MA, Mulder CJJ. Elastic band ligation of hemorrhoids:Flexible gastroscope or rigid proctoscope? World J Gastroenterol. 2007;13:585-587.

27. Wehrmann T, Riphaus A, Feinstein J, Stergiou N. Hemorrhoidal elastic band ligation with flexible videoendoscopes: a prospective, randomized comparison with the conventional technique that uses rigid proctoscopes. Gastrointest Endosc. 2004;60:191-195.

28. Azizi R, Rabani-Karizi B, Taghipour MA. Comparison between Ultroidand rubber band ligation in treatment of internal hemorrhoids. Acta Med Iran. 2010;48(6):389-393.

29. Dilawaiz M, Bashir MA, Rashid A. Hemorrhoidectomy vs rubber band; comparison of post-operative complications. Professional Med J. 2011;18:571-574.

This work is licensed under a Creative Commons Attribution-NonCommercial 3.0 Unported License which allows users to read, copy, distribute and make derivative works for non-commercial purposes from the material, as long as the author of the original work is cited properly. 